\title{
Protocol for a Systematic Review of Policies, Programs or Interventions Designed to Improve Health and Psychosocial Outcomes for Young People Leaving the Out of Home Care System
}

\section{David John Anthony Taylor ( $\nabla$ david.taylor@monash.edu )}

Monash University https://orcid.org/0000-0001-8801-7488

Aron S. Shlonsky

Monash University

Bianca Albers

Centre for Evidence and Implementation

Sangita Chakraborty

Centre for Evidence and Implementation

Jane Lewis

Centre for Evidence and Implementation

Phillip Mendes

Monash University

Geraldine Macdonald

Bristol University

Kevin Williams

The Fostering Network

\section{Protocol}

Keywords: Systematic review, Transitions, Out of home care, Aftercare, Leaving Care, Aging Out

Posted Date: December 8th, 2020

DOI: https://doi.org/10.21203/rs.3.rs-121892/v1

License: (c) (i) This work is licensed under a Creative Commons Attribution 4.0 International License. Read Full License 


\section{Abstract}

\section{Background:}

Relative to their counterparts in the general population, young people who leave, or transition out of, outof-home $(\mathrm{OOHC})$ arrangements, commonly experience poorer outcomes across a range of indicators, including: higher rates of homelessness, unemployment, reliance on public assistance, physical and mental health problems, and contact with the criminal justice system. The age at which young people transition from $\mathrm{OOHC}$ varies between and within some countries, but for most, formal support ceases between the ages of 18 and 21 .

Programs designed to support transitions are generally available to young people toward the end of their $\mathrm{OOHC}$ placement, although some can extend beyond. They often encourage the development of skills required for continued engagement in education, obtaining employment, maintaining housing and general life skills. Little is known about the effectiveness of these programs, or of extended care policies that raise the age at which support remains available to young people after leaving $\mathrm{OOHC}$. This systematic review will seek to identify programs and/or interventions that improve outcomes for youth transitioning from the $\mathrm{OOHC}$ system into adult living arrangements.

\section{Methods:}

Using the Preferred Reporting Items for Systematic Review and Meta-analysis Protocols (PRISMA-P) guidelines, this review will identify programs, interventions and policies that seek to improve health and psychosocial outcomes amongst this population that have been tested using robust controlled methods. Primary outcomes of interest are homelessness, health, education, employment, exposure to violence and risky behaviour. Secondary outcomes are relationships and life skills. A search strategy has been developed that covers eleven databases of published literature in multiple languages. Unpublished literature will also be searched. A meta-analysis will be undertaken if identified studies are suitably heterogenous. Risk of bias will be assessed using tools appropriate to the study methodology. Outcomes across studies will be assessed using the Grading of Recommendations, Assessment, Development and Evaluation (GRADE) methodology.

\section{Discussion:}

Previous reviews were unable to identify any programs or interventions, backed by methodologically rigorous research, that improve outcomes for this population. This review seeks to update this previous work, taking into account changes in the provision of extended care, which is now available in some jurisdictions.

Trial Registration:

PROSPERO: CRD42020146999 


\section{Background}

Youth who experience abuse and neglect by their parents or carers can be placed in out-of-home care $(\mathrm{OOHC})$ in jurisdictions where such formal systems exist. $\mathrm{OOHC}$ takes three major forms: foster care where care services are provided by individuals not necessarily known to the recipient; kinship care where those providing care are connected to the recipient through blood or kin ties; and residential care where care is provided in an institutional setting. Youth can experience one or more of these care types while in $\mathrm{OOHC}$. Whilst the three forms of $\mathrm{OOHC}$ are quite different, they also have similarities: children in homes were often the victims of childhood trauma $(1,2)$; minimal standards of care are required; and financial support, if provided, ceases when youth reach a certain age (3).

$\mathrm{OOHC}$ is a policy area of considerable contemporary cross-national interest (4). The latest available figures for England show that there were 75,420 children in care in 2018. In the same year, 10,460 young people aged 17-18 left care who had spent at least 13 weeks in care between the age of 14 and 16 (5). In Australia, there are approximately 45,000 children in care, with 3,300 of them aged between 15-17 leaving care arrangements in 2018-19 (6). Comparable figures for the United States show that there were 122,000 children aged between 13 and 20 in foster care on 30 September 2018. Of these, approximately 20,000 left care in FY2017, because they reached the legal age of adulthood in their state (7).

Young people who leave or transition out of $\mathrm{OOHC}$ arrangements commonly experience poorer outcomes across a range of indicators relative to their counterparts in the general population, including higher rates of homelessness, unemployment, reliance on public assistance, physical and mental health problems, and contact with the criminal justice system (8-13). These poorer outcomes may be due to pre-existing mental health problems and other challenges arising from their experiences pre-care or whilst in care. They may also be due to insufficient life skills knowledge or training, or may simply be related to the fact that they must fend for themselves at a much earlier age than peers who can rely on their birth families for personal and material support (14).

The age at which young people transition from $\mathrm{OOHC}$ varies between and within some countries - for most, formal support ceases between the ages of 18 and 21 (15). The type and mode of support to care leavers varies between jurisdictions, but can involve formal life skills training programmes, personal adviser or key worker support, mentoring or peer support programs, cash assistance, and housing support. Transition support programmes are generally available to young people toward the end of their care placement, although some extend beyond. They often encourage the development of skills required for continued engagement in education, obtaining employment, maintaining housing and general life skills $(14,16)$.

Young people transitioning from care are often ill-equipped for independent living, and the type and amount of support they receive is insufficient to prevent adverse outcomes $(17,18)$. Considering this, in some jurisdictions, one policy response has been to raise the age at which young people can transition, thereby extending the support available $(19,20)$. 
Since then, reviews have explored various aspects of policies, programs or interventions for youth transitioning from care, but have suffered from a range of weaknesses in either methodology or scope.

Some reviews have limited their scope, either to particular geographies (16), or to interventions delivered while youth were in care $(14,21)$, or to independent living programmes $(14,22,23)$. Some focused on a narrow range of outcomes $(23,24)$. Others have methodological weaknesses, such as not conducting a systematic search (18), not applying a methodological filter or addressing the risk of bias of included studies $(21,25)$, or they failed to critically appraise the effectiveness of the policy or practice interventions included $(22,23,26-28)$.

This review seeks to update this previous work and to include research published in the proceeding period, including that investigating the impact of raising the age at which young people transition.

\subsubsection{Aim}

The aim of this systematic review is to assess the effectiveness of programs and/or interventions designed to improve outcomes for youth transitioning from the out-of-home care system into adult living arrangements. The proposed systematic review question is:

What programs, interventions or services are effective at improving health and psychosocial outcomes for young people leaving the out of home care system?

\section{Methods}

The systematic review has been registered with the International Prospective Register of Systematic Reviews (PROSPERO, http://www.crd.york.ac.uk/PROSPERO, registration number: CRD42020146999).

The review will follow the recommendations as laid out in the Preferred Reporting Items for Systematic Reviews and Meta-Analyses Protocol (PRISMA-P) (29) (see Additional file 1). Findings will be reported as per the PRISMA guidelines (30).

\subsubsection{Criteria for considering studies for this review}

\section{Population}

Youth aged between 16 and 25 who are:

- not living with their birth parents / family; AND

- are in foster care / out-of-home-care / public care / looked after (UK) / state care / government care; AND

- have been placed in care due to concerns related to child maltreatment; AND 
- who are transitioning from care into adult living arrangements.

\section{Intervention}

Programs, interventions or services that:

- provide support and/or assistance to help youth prior to leaving care and/or as they transition and/or after they leave care;

- are delivered in the community;

- support young people transition from their country's statutory out-of-home care systems into adult living.

\section{Comparator}

The following comparisons will be included: intervention/services as usual, another intervention, no intervention, or wait-list control.

\section{Outcome(s)}

Outcomes of interest include the following, at least three months following the age at which eligibility for out of home care terminates in the jurisdiction in which the study takes place. We will also measure outcomes at the point at which any policy, program or intervention ceases.

\section{Primary:}

- Homelessness - we will include measurement that allows us to determine whether or not an individual has or does not have a permanent place to live;

- Health - we will include health outcomes or service usage, including emergency department presentations, hospitalisations, mental health outcomes and sexual health test results;

- Education - we will include measurements of high school completion, high school grades, enrolment in or attainment of a trade qualification and enrolment in or attainment of a university qualification;

- Employment - we will include measurements of whether an individual has a job, their wages, is unemployed or uses unemployment benefits;

- Exposure to violence (as either victim or perpetrator) - we will include any measurement of crime perpetration i.e., whether or not an individual has been arrested, convicted, spent time in a locked setting (jail/prison) or crime victimisation;

- Risky behaviour - we will include measurement of risky behaviour including illicit drug use, alcohol use, risky sexual activity and either the onset or delay of teen pregnancy. 


\section{Secondary:}

- Relationships - we will include measurements of whether individuals have attained or maintained supportive relationships with others, including mentors, peer mentors or supportive peers;

- Life skills - we will include measurements of the attainment of competencies required for independent living; these include, but are not limited to, learning how to budget, attain essential services and perform essential household tasks.

\section{Study design(s)}

The following experimental and quasi-experimental study designs will be included: Randomised Controlled Trials (RCTs) including individual RCTs, cluster RCTs, Step-Wedge designs with random time allocation, and non-equivalent control group designs using parallel cohorts that adjust for baseline equivalence. Difference-in-Difference estimation, synthetic control group methods, studies based on covariate matching, propensity score-based methods, doubly robust methods, regression adjustment, regression discontinuity designs, and instrumental variable estimation. Economic evaluation methodologies: cost-benefit analysis, cost-utility analysis, cost-effectiveness analysis, cost-analysis.

Economic evaluations and qualitative studies will be included if they are conducted as part of a qualifying study and will be used only to inform or deepen our understanding of the quantitative findings.

\subsubsection{Search strategy}

The following databases will be searched for studies published between 1990 and October 302020 using strategies included in (Additional file 2):

- Cochrane Controlled Register of Trials

- CINAHL

- ERIC

- PsycINFO

- MEDLINE

- EMBASE

- Sociological Abstracts

- Social Services Abstracts

- Soclndex

- NHS Economic Evaluation Database

- Health Technology Assessment 


\section{Unpublished literature}

Clearinghouses, government agencies and organisations known to be undertaking or consolidating research in this area from the United States, Europe, Australia, Canada and New Zealand will be examined for unpublished material, including:

- Social Care Online (SCIE)

- International Research Network on Transitions to Adulthood from Care

- Analysis and Policy Observatory

- Australian Institute of Family Studies

- Chapin Hall at the University of Chicago

- California Evidence-Based Clearinghouse for Child Welfare

Authors of each included study will be contacted by email to ascertain if they are aware of any additional literature.

\section{Language of publication}

Any study with an abstract, or translation, available in English, Spanish, Portuguese, Swedish, Norwegian, Danish, German, Japanese, Mandarin or Cantonese will be included during title and abstract screening. If deemed relevant, full text screening and data extraction will be undertaken by a reviewer proficient in that language. In the event that any additional studies are identified in additional languages, the review team will endeavour to locate reviewers proficient in that language to screen and extract data.

\subsubsection{Data collection and management}

Citations identified from the search strategy will be imported into the online systematic review application Covidence (31) for screening. Following PRISMA guidelines, a flowchart will be provided demonstrating the inputs and results of each stage of the review process.

\subsubsection{Study selection}

Title and abstracts will be reviewed separately by two authors working independently, with a third reviewer resolving conflicts when they arise. Subsequently, the full-text versions of all potentially eligible studies will be retrieved and reviewed for eligibility, independently, by two members of the team (with a third review resolving any conflicts) using a priori eligibility criteria. These are included in Table 1 below.

Table 1 - Inclusion and Exclusion criteria by PICO domain 


\begin{tabular}{|c|c|c|}
\hline PICO & Inclusion Criteria & Exclusion Criteria \\
\hline $\begin{array}{l}\text { Study } \\
\text { design }\end{array}$ & $\begin{array}{l}\text { Randomised Controlled Trials (RCT) including: } \\
\text { - } \text { individual RCTs } \\
\text { - } \text { cluster RCTs } \\
\text { allocation-Wedge designs with random time } \\
\text { parallel cohorts that adjust for baseline equivalence } \\
\text { Difference-in-Difference estimation } \\
\text { - Synthetic control group methods } \\
\text { - } \text { covariate matching } \\
\text { - propensity score based methods, } \\
\text { - doubly robust methods } \\
\text { - regression adjustment } \\
\text { - regression discontinuity designs, and } \\
\text { - instrumental variable estimation. } \\
\text { Qualitative studies and economic evaluations will be } \\
\text { included if they are conducted as part of a qualifying } \\
\text { study and will be used only to generate hypotheses, } \\
\text { inform us about the interventions and populations, } \\
\text { and inform or deepen our understanding of the } \\
\text { quantitative findings. }\end{array}$ & $\begin{array}{l}\text { Non-primary studies, } \\
\text { including: } \\
\text { - Literature reviews } \\
\text { - Systematic reviews } \\
\text { - Meta-analysis } \\
\text { counterfactual, including } \\
\text { designs that do not include a } \\
\text { parallel cohort that establish } \\
\text { or adjust for baseline } \\
\text { equivalence, including: } \\
\text { designs } \\
\text { dingle group pre-post } \\
\text { - Control group designs } \\
\text { without matching in time } \\
\text { and establishing baseline } \\
\text { equivalence } \\
\text { - Cross-sectional designs } \\
\text { - Non-controlled } \\
\text { observational (cohort) } \\
\text { designs } \\
\text { - Case-control designs } \\
\text { - Case studies / series } \\
\text { - Surveys } \\
\text { Qualitative designs and } \\
\text { economic evaluations not } \\
\text { undertaken in the context of } \\
\text { an included quantitative } \\
\text { study. }\end{array}$ \\
\hline Population & $\begin{array}{l}\text { Youth aged between } 16 \text { and } 25 \\
\text { Youth in } \mathrm{OOHC} \text { for reasons of child maltreatment, } \\
\text { neglect or risk of child maltreatment, relinquishment, } \\
\text { or lack of provision of support. OOHC settings } \\
\text { include: } \\
\text { foster care } \\
\text { guardianship } \\
\text { kinship care } \\
\text { group care }\end{array}$ & $\begin{array}{l}\text { Youth in OOHC settings for } \\
\text { reasons other than child } \\
\text { maltreatment, neglect, risk of } \\
\text { child maltreatment, } \\
\text { relinquishment, or lack of } \\
\text { provision of support. } \\
\text { Youth who are not in OOHC. } \\
\text { Youth who are currently } \\
\text { incarcerated, including in } \\
\text { youth justice settings. } \\
\text { Youth aged less than } 16 \text { and } \\
\text { greater than } 25 .\end{array}$ \\
\hline
\end{tabular}




\begin{tabular}{|c|c|c|}
\hline Intervention & $\begin{array}{l}\text { Interventions, programs or services delivered in the } \\
\text { home / community. }\end{array}$ & $\begin{array}{l}\text { Interventions, programs or } \\
\text { services delivered in other } \\
\text { settings, for example: } \\
\text { custodial settings. }\end{array}$ \\
\hline Comparison & $\begin{array}{l}\text { Treatment as usual, another intervention, no } \\
\text { intervention, or wait-list control. }\end{array}$ & $\begin{array}{l}\text { Studies using other } \\
\text { comparators. }\end{array}$ \\
\hline \multirow[t]{10}{*}{ Outcome } & Primary Outcomes: & \multirow{10}{*}{$\begin{array}{l}\text { Studies looking at other } \\
\text { outcomes. }\end{array}$} \\
\hline & - Homelessness & \\
\hline & - Health & \\
\hline & - Education & \\
\hline & Employment & \\
\hline & $\begin{array}{l}\text { Exposure to violence (as either victim or } \\
\text { perpetrator) }\end{array}$ & \\
\hline & Risky behaviour & \\
\hline & Secondary Outcomes: & \\
\hline & - Relationships & \\
\hline & - Life skills & \\
\hline Setting & $\begin{array}{l}\text { Countries where a statutory care system for child } \\
\text { maltreatment exists. }\end{array}$ & $\begin{array}{l}\text { Countries where a statutory } \\
\text { care system for child } \\
\text { maltreatment does not exist. }\end{array}$ \\
\hline
\end{tabular}

\subsubsection{Data extraction}

Data extraction will be undertaken by teams of two reviewers, with one reviewer checking the results of the other. Data will be extracted into an online form developed for this review. The following information will be obtained: study design, study outcomes, sample size, location, study timeframe, study population, population demographics, study timeframe, intervention details, effect sizes, implementation outcomes as well as information required to conduct risk of bias assessments.

\subsubsection{Data analysis}

In accordance with Campbell and Cochrane guidelines, we will try to maximise the likelihood of being able to quantitatively synthesise primary and secondary outcomes across studies using a meta-analysis. 
If more than one study with suitable data can be identified, we intend to perform a meta-analysis if the population, intervention, comparison, and outcomes are similar enough to be reasonably combined or can be standardised for comparison. This analysis will be conducted using the R Project for Statistical Computing (32).

For each outcome, we will explore heterogeneity by preparing box plots, forest plots and examining the $\mathrm{I}^{2}$ statistic. If limited heterogeneity is found, we will use a fixed effects model. If there is significant heterogeneity, we will use a random effects model. These models will allow us to estimate the pooled effect size and its $95 \%$ confidence interval for each outcome. For both approaches we will perform a meta-analysis using the longest follow-up period possible for each outcome.

Data from randomised and non-randomised trial designs will not be pooled. Nor will we pool data from non-randomised studies of different study designs.

If the conditions for a meta-analysis are not met, we will describe and synthesise trial findings narratively and/or use descriptive measures (median effect size and range) to describe their effects.

We will synthesise data around each of our primary outcomes (homelessness, health, education, employment, exposure to violence and risky behaviour). If sufficient studies are identified, subgroup analysis will be undertaken based upon the following characteristics: a) study design: randomised control trials vs. non-randomised control trials, b) age at which statutory out of home care support ceases: 18 vs. greater than 18 and c) gender.

For binary outcomes - we will calculate a risk ratio and a 95\% confidence interval. For continuous data if a consistent outcome measure is used, we will calculate the mean difference.

Where different measures are used to examine primary outcomes, we will calculate the standardised mean difference if possible.

Where data from the same outcome are reported in different studies as dichotomous or continuous data, we will transform these (if appropriate) to enable pooled estimates of effect. If missing/illegible we will use the Campbell Collaboration ES calculator (33).

\subsubsection{Evidence assessment}

Risk of bias of included randomised controlled trials will be assessed using the Cochrane Risk of Bias 2 (RoB 2) tool (34). Non-randomised studies will be assessed using the ROBINS-I tool (35). The quality of any economic evaluations will be assessed using guidelines suggested by the Cochrane and Campbell Economics Methods Group (36). Outcomes across studies will be assessed using the Grading of Recommendations, Assessment, Development and Evaluation (GRADE) methodology (37).

\section{Discussion}


Reflecting its place as an emergent policy issue, the volume of research published on care leavers has increased substantially in the last twenty years, but this literature has not been the subject of high- quality synthesis. Therefore, it is an appropriate time for a systematic review to inform ongoing policy and practice discussions about how best to support young people transitioning from care and to shape future research.

This review has a number of advantages over previously published work on this topic, including a) a systematic search of a wide range of databases with no language restrictions, $b$ ) the use of inclusion criteria that prioritise studies with high-quality methodologies, c) the selection of outcomes that reflect health and psychosocial wellbeing, d) the inclusion of policy alongside individual or group-level interventions and e) the use of the GRADE approach to assess the quality of evidence, report results and support knowledge translation.

The results of this review will inform policy discussions in this area in a number of jurisdictions, as they evaluate the merits of providing different modes of transitions support, raising the age at which $\mathrm{OOHC}$ can be provided to young people or a combination of both.

\section{Abbreviations}

GRADE: Grading of Recommendations, Assessment, Development and Evaluation

OOHC: Out of home care

QED: Quasi-experimental design

RCT: Randomised Control Trial

\section{Declarations}

\section{Ethics approval and consent to participate}

Not applicable

\section{Consent for publication}

Not applicable.

\section{Availability of data and materials}

Not applicable. 


\section{Competing interests}

The authors declare that they have no competing interests

\section{Funding}

Funding for this systematic review is provided by the What Works Centre for Children's Social Care (What Works CSC) in the United Kingdom. What Works CSC provided comments on a draft version of this protocol.

\section{Authors' contributions}

AS and DT conceptualised the review question. DT drafted the manuscript. DT, SC and AS developed the search strategy. AS, BA and GM provided methodological advice. PM provided subject matter expertise. $\mathrm{JL}$ is the guarantor of the review. All authors read and approved the final manuscript.

\section{Acknowledgements}

Not applicable.

\section{Endnotes}

Not applicable.

\section{References}

1. Stein BD, Zima BT, Elliott MN, Burnam MA, Shahinfar A, Fox NA, et al. Violence exposure among school-age children in foster care: Relationship to distress symptoms. J Am Acad Child Adolesc Psychiatry [Internet]. 2001;40(5):588-94. Available from: http://dx.doi.org/10.1097/00004583200105000-00019

2. Garland AF, Landsverk JL, Hough RL, Ellis-MacLeod E. Type of maltreatment as a predictor of mental health service use for children in foster care. Child Abus Negl. 1996;20(8):675-88.

3. Bergström M, Cederblad M, Håkansson K, Jonsson AK, Munthe C, Vinnerljung B, et al. Interventions in Foster Family Care: A Systematic Review. Res Soc Work Pract. 2019;

4. Strahl B, van Breda ADP, Mann-Feder V, Schröer W. A multinational comparison of care-leaving policy and legislation. J Int Comp Soc Policy. 2020;1-16.

5. Department for Education. National Statistics: Children looked after in England including adoption: 2017 to 2018 [Internet]. [cited 2020 Jul 1]. Available from: 
https://www.gov.uk/government/statistics/children-looked-after-in-england-including-adoption-2017to-2018

6. Australian Institute of Health and Welfare. Child protection Australia 2018-19 [Internet]. Canberra: Australian Government; 2020. Available from: https://www.aihw.gov.au/reports/childprotection/child-protection-australia-2018-19/data

7. Fernandes-Alcantara AL. Youth transitioning from foster care: Background and federal programs [Internet]. Washington DC; 2019. Available from: https://crsreports.congress.gov/product/pdf/RL/RL34499

8. Doyle JJ. Child protection and child outcomes: Measuring the effects of foster care. Am Econ Rev. 2007;97(5):1583-610.

9. Dworsky A, Napolitano L, Courtney M. Homelessness during the transition from foster care to adulthood. Am J Public Health. 2013;103(SUPPL. 2):318-23.

10. Crawford B, Pharris AB, Dorsett-Burrell R. Risk of serious criminal involvement among former foster youth aging out of care. Child Youth Serv Rev [Internet]. 2018;93(August):451-7. Available from: https://doi.org/10.1016/j.childyouth.2018.08.027

11. Dworsky A, Gitlow E. Employment outcomes of young parents who age out of foster care. Child Youth Serv Rev [Internet]. 2017;72:133-40. Available from:

http://dx.doi.org/10.1016/j.childyouth.2016.09.032

12. Fowler PJ, Marcal KE, Zhang J, Day O, Landsverk J. Homelessness and aging out of foster care: A national comparison of child welfare-involved adolescents. Child Youth Serv Rev [Internet]. 2017;77(December 2016):27-33. Available from: http://dx.doi.org/10.1016/j.childyouth.2017.03.017

13. Greeno EJ, Lee BR, Tuten M, Harburger D. Prevalence of Substance Use, Housing Instability, and SelfPerceived Preparation for Independence Among Current and Former Foster Youth. Child Adolesc Soc Work J. 2019;36(4):409-18.

14. Donkoh C, Underhill K, Montgomery P. Independent living programmes for improving outcomes for young people leaving the care system. Cochrane Database Syst Rev [Internet]. 2006;8. Available from: http://doi.wiley.com/10.1002/14651858.CD005558.pub2

15. Gypen L, Vanderfaeillie J, De Maeyer S, Belenger L, Van Holen F. Outcomes of children who grew up in foster care: Systematic-review. Child Youth Serv Rev [Internet]. 2017;76:74-83. Available from: http://dx.doi.org/10.1016/j.childyouth.2017.02.035

16. O'Donnell R, Hatzikiriakidis K, Mendes P, Savaglio M, Green R, Kerridge G, et al. The impact of transition interventions for young people leaving care: a review of the Australian evidence. Int $J$ Adolesc Youth [Internet]. 2020;25(1):1076-88. Available from: https://doi.org/10.1080/02673843.2020.1842216

17. Kushel MB, Yen IH, Gee L, Courtney ME. Homelessness and Health Care Access After Emancipation. Arch Pediatr Adolesc Med [Internet]. 2007;161(10):986-933. Available from: http://archpedi.jamanetwork.com/article.aspx?doi=10.1001/archpedi.161.10.986 
18. Heerde JA, Hemphill SA, Scholes-Balog KE. The impact of transitional programmes on post-transition outcomes for youth leaving out-of-home care: a meta-analysis. Heal Soc Care Community. 2018;26(1):e15-30.

19. Mendes $\mathrm{P}$, Rogers J. Young people transitioning from out-of-home care: What are the lessons from extended care programmes in the usa and england for Australia? Br J Soc Work. 2020;50(5):151330.

20. van Breda AD, Munro ER, Gilligan R, Anghel R, Harder A, Incarnato M, et al. Extended care: Global dialogue on policy, practice and research. Child Youth Serv Rev [Internet]. 2020;119(April):105596. Available from: https://doi.org/10.1016/j.childyouth.2020.105596

21. Everson-Hock ES, Jones R, Guillaume L, Clapton J, Duenas A, Goyder E, et al. Supporting the transition of looked-after young people to independent living: A systematic review of interventions and adult outcomes. Child Care Health Dev. 2011;37(6):767-79.

22. Yelick A. Research Review: Independent living programmes: the influence on youth ageing out of care (YAO). Child Fam Soc Work. 2017;22(1):515-26.

23. Liu C, Vazquez C, Jones K, Fong R. The impact of independent living programs on foster youths' educational outcomes: A scoping review. Child Youth Serv Rev [Internet]. 2019;98(September 2018):213-20. Available from: https://doi.org/10.1016/j.childyouth.2019.01.006

24. Randolph KA, Thompson H. A systematic review of interventions to improve post-secondary educational outcomes among foster care alumni. Child Youth Serv Rev [Internet]. 2017;79(July):60211. Available from: http://dx.doi.org/10.1016/j.childyouth.2017.07.013

25. Woodgate RL, Morakinyo O, Martin KM. Interventions for youth aging out of care: A scoping review. Child Youth Serv Rev [Internet]. 2017;82(July):280-300. Available from: http://dx.doi.org/10.1016/j.childyouth.2017.09.031

26. Naccarato T, DeLorenzo E. Transitional youth services: Practice implications from a systematic review. Child Adolesc Soc Work J. 2008;25(4):287-308.

27. Häggman-Laitila A, Salokekkilä P, Karki S. Integrative review of the evaluation of additional support programs for care leavers making the transition to adulthood. J Pediatr Nurs [Internet]. 2020;54:6377. Available from: https://doi.org/10.1016/j.pedn.2020.05.009

28. Greeson JKP, Garcia AR, Tan F, Chacon A, Ortiz AJ. Interventions for youth aging out of foster care: A state of the science review. Child Youth Serv Rev [Internet]. 2020;113(April):105005. Available from: https://doi.org/10.1016/j.childyouth.2020.105005

29. Shamseer L, Moher D, Clarke M, Ghersi D, Liberati A, Petticrew M, et al. Preferred reporting items for systematic review and meta-analysis protocols (prisma-p) 2015: Elaboration and explanation. BMJ [Internet]. 2015;349(January):1-25. Available from: http://dx.doi.org/doi:10.1136/bmj.g7647

30. Moher D, Liberati A, Tetzlaff J, Altman DG, The PRISMA Group. Preferred Reporting Items for Systematic Reviews and Meta-Analyses: The PRISMA Statement. PLoS Med [Internet]. 2009;6(7):e1000097. Available from: https://journals.plos.org/plosmedicine/article/file? id=10.1371/journal.pmed.1000097\&type=printable 
31. Veritas Health Innovation. Covidence systematic review software. Melbourne;

32. R Core Team. R: A language and environment for statistical computing [Internet]. Vienna: $\mathrm{R}$ Foundation for Statistical Computing; 2020. Available from: http://www.r-project.org/

33. Wilson DB. Practical Meta-Analysis Effect Size Calculator [Internet]. [cited 2020 Sep 14]. Available from: https://campbellcollaboration.org/research-resources/effect-size-calculator.html

34. Sterne JAC, Savović J, Page MJ, Elbers RG, Blencowe NS, Boutron I, et al. RoB 2: A revised tool for assessing risk of bias in randomised trials. BMJ. 2019;366:1-8.

35. Sterne JA, Hernán MA, Reeves BC, Savović J, Berkman ND, Viswanathan M, et al. ROBINS-I: A tool for assessing risk of bias in non-randomised studies of interventions. BMJ. 2016;355:4-10.

36. Higgins J, Green S. Cochrane Handbook for Systematic Reviews of Interventions [Internet]. 2011. Available from: www.handbook.cochrane.org

37. Guyatt GH, Oxman AD, Vist GE, Kunz R, Falck-Ytter Y, Alonso-Coello P, et al. GRADE: an emerging consensus on rating quality of evidence and strength of recommendations. BMJ [Internet]. 2008;336(924). Available from: https://www.bmj.com/content/336/7650/924

\section{Supplementary Files}

This is a list of supplementary files associated with this preprint. Click to download.

- Additionalfile1.docx

- Additionalfile2.pdf 